\title{
Management of Refractory Posterior Epistaxis by Sphenopalatine \\ Artery (SPA) Cauterization
}

Unit chief Rhinology and Allergy Unit Ganesh Man Singh Memorial Academy of ENT Head \& Neck Studies,

Tribhuvan University Teaching Hospital, Kathmandu, Nepal

\section{Correspondence to}

B Pradhan

Rhinology and Allergy Unit,

Ganesh Man Singh Memorial Academy of ENT Head \& Neck Studies,

Tribhuvan University Teaching Hospital,

Kathmandu, Nepal.

Email:bibhuduga@yahoo.com

Introduction: in the form of chemical cauterization, anterior nasal packing (ANP) and posterior nasal packing (PNP) anterior ethmoidal and external carotid artery ligation are not entirely satisfactory because of their morbidity, high failure rate and complications.

Objective:

To assess the effectiveness of SPA cauterization in posterior nose bleed.

Materials \& Methods:

The experience of endoscopic sphenopalatine artery cauterization under general anesthesia in 7 patients has been described. All patients had anterior nasal packing, use of invotec for posterior nasal bleed and some patients had classical posterior nasal packing but all of them had failed to control bleeding.

Results:

Epistaxis was controlled in all 7 patients after sphenopalatine artery cauterization.

\section{Disussion:}

The technique of sphenopalatine artery cauterization is described. The technique is simple, effective without any morbidity and complications, and is applied in patients where ANP and PNP failed to control the bleeding We should apply this technique in patients with posterior bleed before taking up the patient for classical posterior nasal packing

Conclusion:

Though it is a preliminary result, endoscopic cauterization of sphenopalatine artery seems to be safe, simple and effective procedure for the management of refractory posterior epistaxis.

Key Words: Epistaxis, Sphenopalatine artery, endoscopic surgery

\section{INTRODUCTION:}

Intractable epistaxis remains a challenge for ENT surgeons. Sometimes it can be life threatening because of aspiration, hypotension, anemia and associated co-morbidities. ${ }^{1}$ Most cases of epistaxis are managed conservatively with chemical cautery or packing. When this procedure fails, artery ligation is considered. Previously ligation of internal maxillary artery through transantral approach was commonly used. However, this technique was often associated with complications like facial swelling, facial numbness, oroantral fistula and also failure rate of $10-15 \% .^{2}$ More recently clipping or cauterization of sphenopalatine artery (SPA) has been adopted, which is associated with few or no complications and short hospital stay. ${ }^{3}$ Endoscopic sphenopalatine artery cauterization is now a recognized and frequently used treatment for control of intractable posterior epistaxis. However, locating the sphenopalatine foramen in bleeding patient can be very difficult, thus the good knowledge of the local anatomy is essential. ${ }^{4}$ For effective decrease in arterial pressure, ligation is best undertaken as close to the bleeding site as possible. To this end, endoscopic ligation of the SPA which is at point distal to all retrograde and anastomatic connections, is an effective and logical site to direct treatment. ${ }^{5}$

\section{MATERIALS \& METHODS:}

The author has recently treated seven patients with intractable epistaxis by endoscopic sphenopalatine artery cauterization. All the patients were initially treated by conventional anterior nasal packing (ANP) with BIPP, and when it failed either invotec balloon catheter or classical posterior nasal packing was done. Patients still bleeding with above measures were subjected to SPA cauterization under general anesthesia. Four of our patients were hypertensive. No patient had an identifiable systemic coagulation defect (Table 1).

Table 1: Details of patients who underwent SPA cauterization

\begin{tabular}{|c|l|l|c|}
\hline Age/Sex & \multicolumn{1}{|c|}{ Presentation } & Side & $\begin{array}{l}\text { Associated } \\
\text { disease }\end{array}$ \\
\hline $36 / M$ & $\begin{array}{l}\text { Recurrent Epistaxis requiring } \\
\text { ANP twice and invotec } \\
\text { insertion }\end{array}$ & Right & - \\
\hline $58 / M$ & $\begin{array}{l}\text { Recurrent Epistaxis } \\
\text { requiring ANP and PNP }\end{array}$ & Right & HTN \\
\hline $58 / M$ & $\begin{array}{l}\text { Recurrent Epistaxis } \\
\text { requiring ANP twice PNP }\end{array}$ & Right & $\begin{array}{l}\text { HTN and vestibular } \\
\text { stenosis }\end{array}$ \\
\hline $22 / M$ & $\begin{array}{l}\text { Recurrent Epistaxis requiring } \\
\text { ANP invotec insertion }\end{array}$ & Left & - \\
\hline $48 / F$ & $\begin{array}{l}\text { Recurrent Epistaxis requiring } \\
\text { ANP invotec insertion }\end{array}$ & Right & HTN with anemia \\
\hline $48 / M$ & $\begin{array}{l}\text { Recurrent Epistaxis } \\
\text { with repeated ANP }\end{array}$ & Left & HTN \\
\hline $49 / F$ & $\begin{array}{l}\text { Recurrent Epistaxis } \\
\text { with ANP and PNP }\end{array}$ & Left & - \\
\hline
\end{tabular}

$\mathrm{HTN}=$ hypertension

\section{SURGICAL PROCEDURE:}

The procedure was done under general anesthesia. At first, $1 \mathrm{ml}$ of $2 \%$ xylocaine with adrenaline 1:200,000 was injected by an insulin syringe into the greater palatine foramen. This was intended to reach the terminal tributaries of the internal maxillary artery in the pterygopalatine fossa and to cause vasoconstriction. In addition, a high volume of saline $(3 \mathrm{ml})$ was also injected at the same site to pressure tamponade the vessel (fig.1). The greater palatine foramen is located between the 2nd and 3rd molar teeth $1 \mathrm{~cm}$ medial to this area. ${ }^{5}$ $2 \%$ Xylocaine with adrenaline was also injected in the lateral wall of the nasal cavity. Middle turbinate was gently medialized 
and $1.5 \mathrm{~cm}$ mucosal incision was made posterior inferior to the bulla ethmoidalis by otology round knife (fig. 2 A \& B). A mucoperiostial flap was elevated in the posterior fontenelle of the medial maxillary and palatine bones. The flap was raised further posterosuperiorly until the sphenopalatine foramen was encountered. We looked for the crista ethmoidalis bony ridge at the sphenopalatine foramen. The artery was seen passing
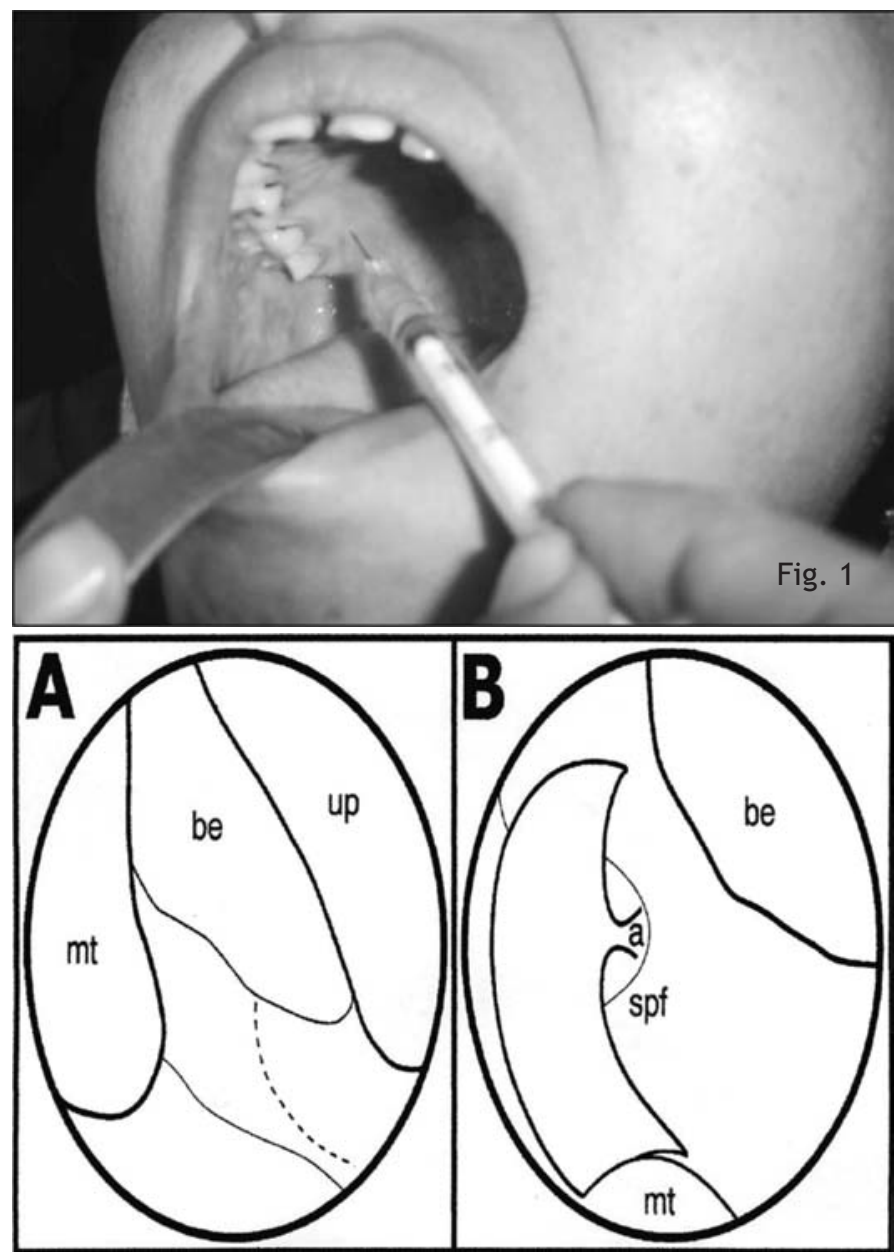

Fig. 2 (A) \& (B). Schematic representation of the surgical approach. (A) up= uncinate process; be = bulla ethmoidalis; $\mathrm{mt}=$ middle turbinate; dotted line = line of incision. (B) $\mathrm{spf}=$ sphenopalatine formen; $a=$ artery.

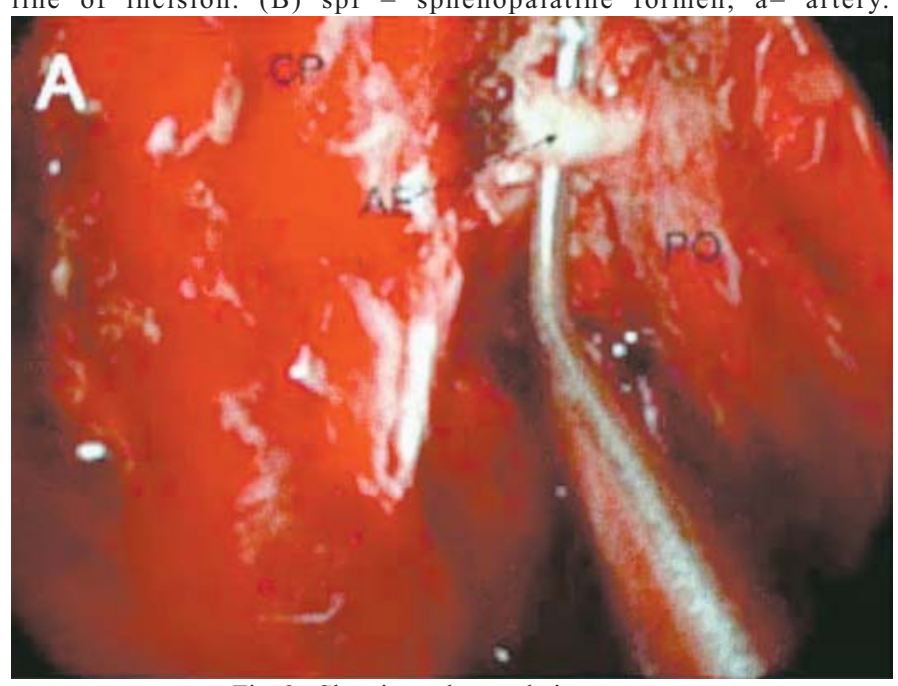

Fig. 3 : Showing sphenopalatine artery medially and in the mucosal fold (fig.3). The artery at the main trunk or after the bifurcation was diathermised with special long bladed bipolar cautery. Idealy metal clips should be placed in the artery but since it is not available in Nepal, we used bipolar cautery. Another advantage of bipolar cautery was that we could diathermise in multiple sites. The flap was replaced back and gentle unilateral BIPP pack was done and kept for 24 hours.

\section{RESULTS:}

The procedure took around 45 minutes. No patients had any complications due to this procedure. All patients had successful control of epistaxis. One patient who had vestibular narrowing due to repeated PNP had mild nasal bleed 3 months after surgery, which was controlled by ANP. On nasal endoscopy of this patient, there was crusting inside the nose and also vestibulitis. So neosporin ointment was prescribed for it. No other patients had any other complications. All seven patients were discharged on $3^{\text {rd }}$ post operative day, they were asked to take oral ciprofloxacin $500 \mathrm{mg}$ BID for one week, nasal douching with normal saline and were asked to use neosporin ointment inside the nose to prevent crusting and re-bleeding.

\section{I S S C U S S I O N :}

Management of epistaxis can be very difficult at times especially where there is posterior bleeding. Treatment options for epistaxis includes chemical cautery, anterior nasal packing, posterior nasal packing, septoplasty with bilateral flap elevation, internal maxillary artery ligation, external carotid artery or anterior ethmoidal artery ligation. All these masures have high failure rate ranging from $26-52 \%$. 6,7 Posterior nasal packing is associated with discomfort, mucosal trauma and morbidity due to hypoxia. External carotid artery ligation has high failure rate due to extensive anastomosis distal to the site of ligation. ${ }^{6,8}$ Recent management of epistaxis includes angiography and embolization of the bleeding vessels and endoscopic clipping and cauterization of sphenopalatine artery. Angiography and embolization of maxillary artery requires an experience interventional radiologists, which facility is not available in many centres. Moreover this procedure may be associated with serious neurological complications. 9,10 The microscopic surgical approach to the sphenopalatine foramen was first described by Pradesh. ${ }^{11}$ An approach for vidian neurectomy, after the advancement in technique of nasal endoscopy, endoscopic SPA ligation for the management of posterior epistaxis was tried, later it became popular for refractory epistaxis. Multiple studies ${ }^{12-18}$ have reported a success rate of over $90 \%$ with no significant complications. All our seven patients had good control of epistaxis with this procedure without any complications. Thereby, avoiding the morbidity associated with prolong nasal packing and other external surgical approaches.

\section{CONCLUSION:}

Though it is a preliminary result, endoscopic cauterization of sphenopalatine artery seems to be safe, simple and effective procedure for the management of refractory posterior epistaxis. 
Because of its minimal morbidity, high effectiveness we plan to practice this procedure in patients where anterior nasal packing does not control the bleeding. Posterior nasal pack is very painful for the patient, also it may cause hypoxia and also there is extensive laceration of nasal mucosa after packing causing difficult to raise the mucoperiostial flap for SPA cauterization.

\section{REFERENCES:}

1. Hadoura L, Douglas C, McGarry GW, Young D. Mapping surgical coordinates of the sphenopalatine foramen:surgical navigation study. The journal of Laryngology \& Otology 2009;123:742-5.

2. McDonald TJ, Pearson BW. Follow up on maxillary artery ligation for epistaxis. Arch Otolaryngol 1980;106:635-8

3. Feusi B, Holzmann D, Steurer J. Posterior epistaxis:systematic review on the effectiveness of surgical therapies. Rhinology 2005;43:300-4.

4. McGarry GW. Nasal endoscope in posterior epistaxis: a preliminary evaluaton.J Laryngol Oto1991;105:428-31

5. Thakar A, Sharan CJ. Endoscopic sphenopalatine artery ligation for refractory posterior epistaxis. Indian Journal of Otolaryngology and Head \& Neck Surgery, 2005; Vol. 57, No. 4:300-3.

6. Schaitkin B, Strauss M, Houck JR. Epistaxis: medical versus surgical therapy, a comparison of efficacy complications and economic considerations. Laryngoscope 1987;97:1392-5.

7. Shaw CB, Wax MK, Wetmore SJ. Epistaxis: a comparison of treatment. Otolaryngol Head Neck Surg 1993;109:60-5.

8. Spafford P, Durham JS. Epistaxis: efficacy of arterial ligation and long term outcome. J Otolaryngol 1992;21:252-6

9. Siniluoto TM, Leinonen AS, Kartunnen AK. Embolisation for management of posterior epistaxis. Arch Otolaryngol 1993;119:837-41.

10. Metson R, Hanson DG. Bilateral facial nerve paralysis following arterial embolisation for epistaxis. Otolaryngol Head and Neck Surg 1983;91;299-302.

11. Prades J. endonasal de la Fosse pterygo-mexilaire. LXXIII Congress France: Rendus des seance';1980;290-6.

12. Sharp HR, Rowe-Jones JM, Biring GS, Mackay IS. Endoscopic ligation of diathermy of the sphenopalatine artery in persistant epistaxis. J Laryngol Otol 1997;111:1047-50.

13.Pritkin JB, Calearelli DD, Panje WR. Endoscopic ligation of the internal maxillary artery for treatment of intractable posterior epistaxis. ANN Otol Rhinol Laryngol 1998;107:85-91.

14. Srinivasan V, Sheraman JW, Sullivan G. Surgical Management of intractable epistaxis: audit of results. J Laryngol Otology 2000;114:697.

15. Wiorowski M, Schultz p, Perrot JB, Gentine A, Derby C. Indications and results of cauterization by endoscopic approach of the sphenopalatine artery in severe posterior epistaxis. Auris Nasus Larynx 2004;31:131-3.

16. Elwany S, Kamel T, Mekhamer A. Pneumatic nasal catheters: approach to the maxillary artery may cause damage to the advantages and drawbacks. J Laryngol Otol 1986;100:641-7

17. White PS. Endoscopic ligation of the sphenopalatine artery: a preliminary description. J Laryngol Otol 1996;110:27-30

18. Reza Nouraei SA, Chir MBB, Maani T, Hajioff D, Saleh HA, Mackay IS. Outcome of Endoscopic sphenopalatine artery occulusion for intractable epistaxis : A 10- Year experience. Laryngoscope August 2007;117:1452-7. 